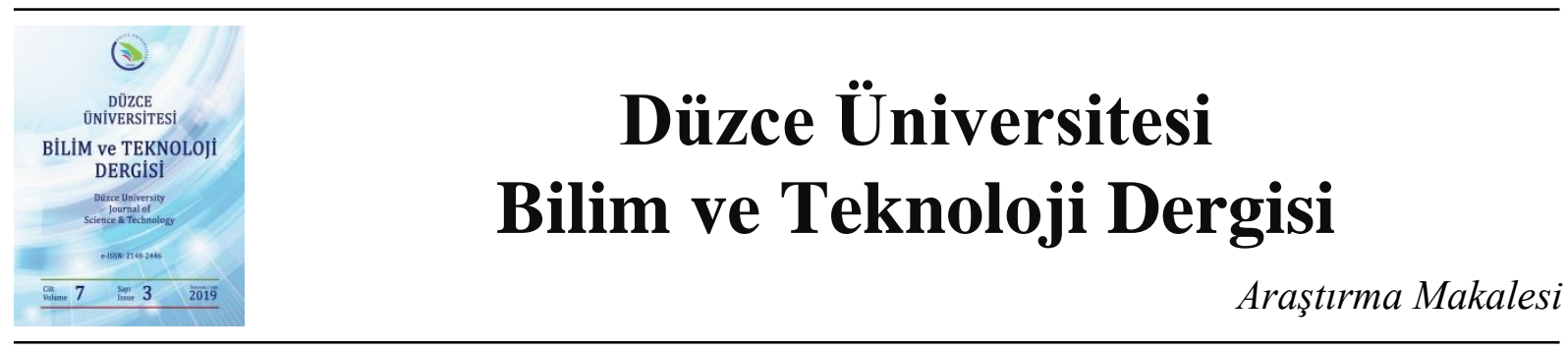

\section{Betonarme Bir Okul Binasının 2018 Deprem Yönetmeliğine Göre İncelenmesi}

\author{
iD Tuncay KAP ${ }^{\mathrm{a}, *}$, iD Ercan ÖZGAN ${ }^{\mathrm{b}}$, iD Metin Mevlüt UZUNOĞLU \\ *Düzce Üniversitesi, Düzce Meslek Yüksekokulu, Inşaat Bölümü, 81010, Düzce, Türkiye \\ ${ }^{b}$ Düzce Üniversitesi, Sanat, Tasarım ve Mimarlık Fakültesi, Mimarlık Bölümü, 81600, Düzce, Türkiye \\ ${ }^{c}$ Düzce Üniversitesi, Teknoloji Fakültesi, Inşaat Mühendisliği Bölümü, 81620, Düzce, Türkiye \\ *Sorumlu yazarin e-posta adresi: tuncaykap@duzce.edu.tr \\ DOI : 10.29130/dubited.506373
}

\begin{abstract}
ÖZET
$\mathrm{Bu}$ çalışmada ülkemiz toprak alanlarının büyük bir çoğunluğu deprem bölgesinde olması nedeniyle Çevre ve Şehircilik Bakanlığı, deprem etkisi altında yeni binaların tasarımında ve mevcut binaların değerlendirilmesinde değişiklikler yaparak depreme dayanıklı yapıların inşa edilmesini hedeflemektedir. Bu amaçla 2018 Deprem yönetmeliği hazırlanmıştır. Yönetmelikte, mevcut binaların zemin özelliklerinin nasıl belirleneceği belirtilmiştir. $\mathrm{Bu}$ kapsamda, zemin grupları taşıma gücü açısından en yüksekten en düşüğe doğru A, B, C, D, E, F olarak 6 farklı grupta tanımlanmıştır. Bu çalışmada, 1999 Marmara ve Düzce depremlerinden etkilenmiş ve taşıma gücü yüksek bir zeminde inşa edilmiş bir okul binasının deprem performans analizi yapılmıştır. Binadaki taşıyıcı elemanların kapasiteleri belirlenmiş ve deprem dayanımları değerlendirilmiştir. Binanın içinde ve dışında temel muayene çukurları açılarak temel şekli ve boyutları belirlenmiştir. Sahada zeminin taşıma gücü ve bazı özelliklerin belirlenmesi amacıyla 3 adet sondaj kuyusu açılmıştır. Binanın taşıyıcı elemanları üzerinde donatı çap ve paspayları ölçülerek kolon ve kirişlerden yönetmelikte belirtilen sayıda karot numuneleri alınarak laboratuar ortamında beton basınç dayanımları bulunmuştur. Proje verilerinden elde edilen bilgiler 2018 yönetmeliğine göre "STA4-V14.1" paket programı ile analiz edilmiştir.
\end{abstract}

Anahtar Kelimeler: Deprem, Betonarme, Deprem yönetmeliği, Zemin, Performans analizi

\section{Investigation of a Reinforced Concrete Building according to 2018 Earthquake Regulation}

\begin{abstract}
In this study, the Ministry of Environment and Urbanization aims to construct earthquake resistant structures by making changes in the design of existing buildings and the evaluation of existing buildings under the influence of earthquakes. For this purpose, 2018 Earthquake Regulation was prepared. The regulation states how to determine the floor characteristics of existing buildings. In this context, soil groups are defined in 6 different groups as A, B, C, D, E, F from the highest to the lowest. In this study, the earthquake performance analysis of a school building, which was built on a high-strength ground, was affected by the 1999 Marmara and Düzce earthquakes. The capacities of the carrier elements in the building were determined and earthquake resistance
\end{abstract}


was evaluated. The basic shape and dimensions were determined by opening the basic inspection pits inside and outside the building. In order to determine the bearing capacity of the ground and some features, 3 boreholes were opened. Measurements of reinforcement diameters and mats on the bearing elements of the building and columns and beams from the number of cores specified in the regulation by taking samples in the laboratory concrete compressive strength was found. The data obtained from the project data were analyzed according to the 2018 regulation with the A STA4-V14.1 8 package program.

Keywords: Earthquake, Reinforcement, Regulation, Soil, Analysis of performance

\section{GiRIS}

$T^{2}$ Ürkiye, yeryüzünün en aktif deprem kuşaklarından birisi olan, Akdeniz, Alp, Himalaya deprem kuşağ 1 içerisinde yer almaktadır. Alp sıradağları Asya ile Avrupa kıtalarının birbirlerine göre göreceli hareketlerinin oluşturduğu sıkıştırıcı kuvvetlerin etkisiyle meydana gelmiştir. Benzer şekilde Himalayar da Hindistan ile Asya kıtasının birleşmesi sonucunda oluşmuştur[1]. Türkiye'de meydana gelen depremler, dinamik özellikleri nedeniyle beklenenin çok üzerinde yapı hasarına neden olmaktadır. Buna karsın, günümüz bilim ve teknolojisi, yüksek şiddetli depremlerde bile yapıların yıkılmadan ayakta durabilmesini ve depremden sonra da kullanılabilir olmasını sağlayacak düzeydedir. Bu teknolojik bilgiyi çok daha yetkin olarak kullanabilen Japonya, ABD ve Yeni Zelanda gibi ülkelerde yaşanan depremler, Türkiye'de olan depremlerden daha şiddetli olmasına rağmen çok daha az can ve mal kaybına sebep olmaktadır [2]. Yapılar için, sabit düşey yükler altında, yatay yüklerin kademeli artırılmasıyla yapılan doğrusal olmayan hesap yöntemine "Statik itme Yöntemi" denir [2]. Bu yöntem, binanın deprem esnasındaki davranışını daha gerçekçi olarak temsil ettiği için, hesaplamaların daha doğru bir şekilde yapılmasına imkan tanımaktadır [3]. Deprem performansı "tanımlanan deprem etkisi altında bir binada oluşabilecek hasarların düzeyine ve dağılımına bağlı olarak belirlenen yapı güvenliği durumunun belirlenmesi” diye tanımlanmaktadır. Mevcut bir binanın deprem performansının belirlenmesi amaciyla ilk olarak binanın mevcut durumunun yerinde tespit edilmesi gerekmektedir. Bu amaçla inceleme yapılacak binadan toplanacak binanın sistem özellikleri, taşıyıcı eleman boyutları, malzeme ve detaylarla ilgili bilgilerin kapsamı ve zemin parametreleri yönetmelikte ayrıntılı olarak belirtilmiştir. Zemin koşulları ile ilgili hususlar yönetmeliğin 16. Bölümünde ifade edilmiştir [3].

Deprem etkisi altında tasarımı yapılacak yeni binalar ile deprem performansı değerlendirilecek veya güçlendirilecek mevcut binalar için gerekli zemin araştırmalarının kapsamı, zemin koşullarının, sınıf ve parametrelerinin belirlenmesi, bina temellerinin ve çevre bodrum perdelerinin deprem etkisi altında tasarımı, yapı-zemin etkileşimi analizleri ve zemin öncelikle bu Yönetmeliğin Bölüm 16.1 de verilen kural ve koşullara uyularak yapılması önerilmiştir [4].

Depreme dayanıklı yapı tasarımı ilkelerine göre yapılar ekonomik ömürleri içinde en az bir kez olması beklenen yüksek şiddetteki depremlerde can kaybını önleyecek dayanımda yapılırlar[5].

Yap1 sistemi, yapısal davranışı etkileyen en önemli faktörlerden birisidir[6]. Çerçeveli sistemler deprem sırasında, yatay yükleri düğüm noktalarındaki elemanların rijitlikleri ile orantılı olarak karşılamaktadır. Betonarme çerçeveli sistemler yatay yük etkisi altında fazla miktarda yer değiştirme yapmaktadır. Çerçeveli betonarme taşıyıcı sistemler, süneklik, dayanım ve rijitlik özellikleri ile yatay 
yüklerin taşınmasını sağlamaktadır[7]. 2018 Deprem yönetmeliğine göre binanın üç boyutlu performans analizi yapılarak yapının performansı değerlendirilmektedir [8-14].

Tunç vd. 2007 ve 2018 yönetmeliklerini farklılıkları ve benzerlikleri açısından karşılaştırmışlardır. Çalışma kapsamında Sapanca' da yapılması düşünülen 10 katı bir ofis binasının deprem analizi her iki yönetmeliğe göre ETABS programı kullanılarak yapılmıştır. Sonuç olarak tasarım iç kuvvetlerindeki artış irdelenmiş ve yeni yönetmelikte tasarım iç kuvvetlerinde \% 20-\% 25 arasında artış olduğu sonucuna ulaşılmıştır [15].

\section{MATERIALS AND METHOD}

Çalışma kapsamında Konuralp Çok Programlı Lisesi binasında taşıyıcı sistem elemanlarının kapasitelerinin belirlenmesi, deprem dayanımlarının değerlendirilmesinde kullanılacak eleman detay ve boyutları, taşıyıcı sistem geometrisi ve malzeme özellikleri detaylı olarak incelenmiştir. Okul binasının taban alanı $614,50 \mathrm{~m}^{2}$ olup yapı, zemin ve 3 normal kattan oluşmaktadır (Şekil 1).

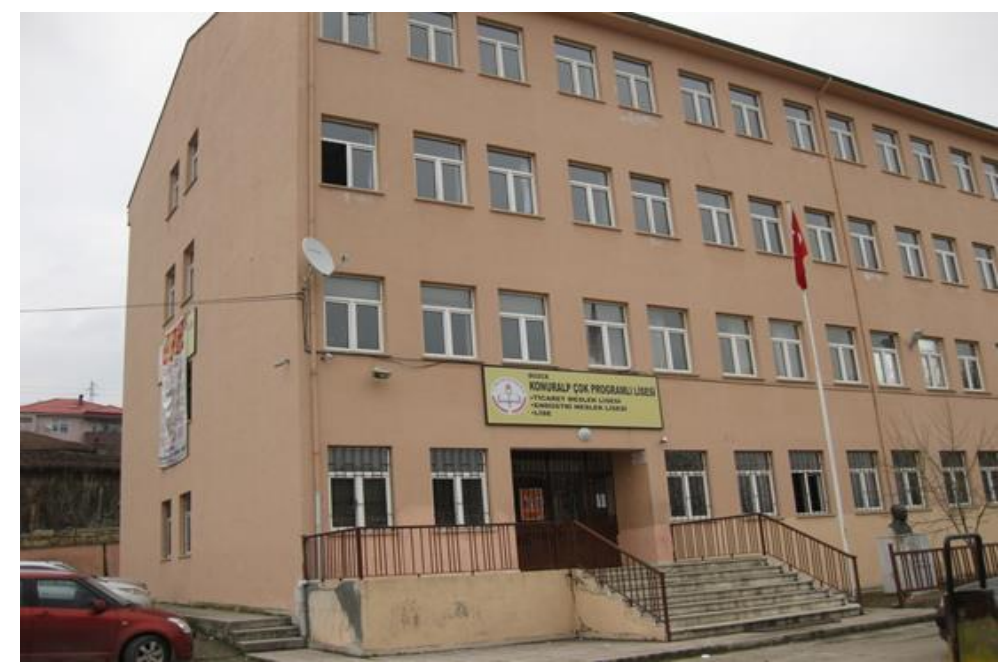

Şekil 1. Konuralp Çok Programlı Lisesi giriş cephe görüntüsü

Zemin Etüt Raporundan Okul binasının dış tarafında ve içinde açılan muayene çukurlarından temel derinliği $\mathrm{Df}=0,9 \mathrm{~m}$ ve temel genişliği $\mathrm{B}=2,7 \mathrm{~m}$ olarak ölçülmüştür. Zemin Etüt Raporunda, incelenen binanın zemininde 2 adet $4,5 \mathrm{~m}$ derinlikte sondaj yapılmıştır.

\section{BULGULAR}

İncelenen binanın taşıyıcı sistemi betonarme karkas olup binada yapılan röleve çalışmalarından sonra kat planları çizilmiştir. Binanın içinde ve dışında zemin muayene çukurları açılarak temel yapısı, temel özellikleri ve yer altı su seviyesi gibi parametreler belirlenmiştir. Yapının temel özelliklerinin belirlenebilmesi amacı ile binanın içinden ve dışından temel çukurları açılarak temelin boyutları, temel derinliği ve temel şekli belirlenmiştir (Şekil 2). 


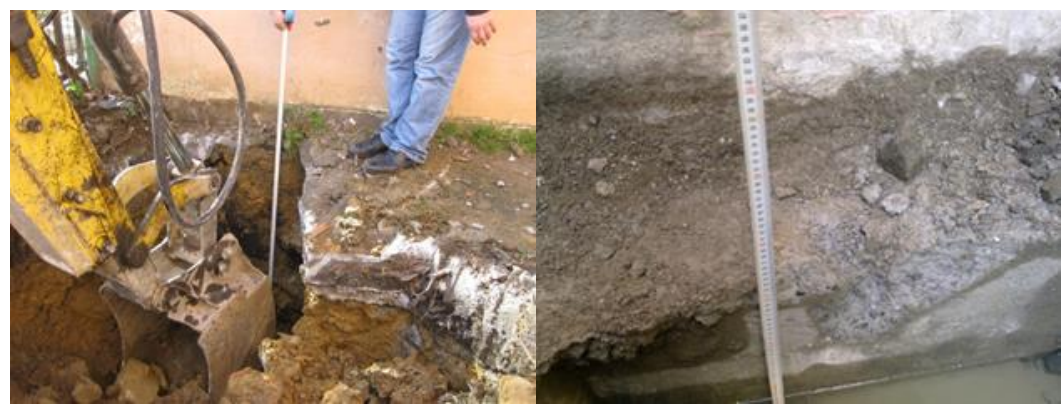

Şekil 2. Binanın dışından ve içinden açılan temel çukurları

Zemin Etüt Raporunda, incelenen binanın zemininde $4.5 \mathrm{~m}$ derinlikte 2 adet kuyuda sondaj çalışmalarının yapıldığı ve bu kuyularda yer altı suyuna rastlanmamıştır. Sondaj kuyularından alınan numunelerin üzerinde Nokta Yükleme deneyinin yapılmış ve en düşük taşıma gücü değerinin 12.81 $\mathrm{kg} / \mathrm{cm}^{2}$ ile SK-1 kuyusundan 3,0-4,5 m derinlikten alınan numunede elde edilmiştir. Güvenlik katsayısı 10 olarak alındığında Zeminin Emniyetli Taşıma Gücü qem=1.28 kg/ $\mathrm{cm}^{2}$ olarak hesaplanmıştır. İncelenen zeminde 1 adet sismik çalışma yapılmış olup S1 için 1 . tabakada zemin emniyet gerilmesinin $0.96 \mathrm{~kg} / \mathrm{cm}^{2}$ ve 2 . tabakada ise zemin emniyet gerilmesinin de $4.48 \mathrm{~kg} / \mathrm{cm}^{2}$ olduğu belirlenmiştir. İncelenen zeminin, Deprem Bölgelerinde Yapılacak Yapılar Hakkında Yönetmeliğe göre B Zemin Grubunda ve Z1 Yerel Zemin sınıfında bol kırıklı kumtaşı olup çok zayıf kaya olduğu belirlenmiştir. Yapının 2007 yönetmeliğine uygunluğunun analiz edilebilmesi için yönetmelik kapsamında betonarme elemanlardan beton karot numuneler alınmıştır. Binadan 2007 Yönetmeliğine göre her kattan 7'şer adet olmak üzere toplam 28 adet karot numune alınmıştır. Karot numuneler TSEN 12504-1, TS EN 12390-3 standartlarına göre alınmış olup, hesaplamalar TS EN 13791 standardına uygun yapılmıştır. Deneyler sonucu elde edilen beton basınç dayanımları aşağıda verilmiştir (Tablo 2).

Tablo 2. Karot numunelerin basınç dayanımları

\begin{tabular}{|c|c|c|}
\hline Numune No & Alındığı yer & $\begin{array}{l}\text { Basınç değeri } \\
\left(\mathrm{N} / \mathrm{mm}^{2}\right)\end{array}$ \\
\hline 1 & Zemin Kat Kolon 1 & 19,88 \\
\hline 2 & Zemin Kat Kolon 2 & 12,35 \\
\hline 3 & Zemin Kat Kolon 3 & 18,05 \\
\hline 4 & Zemin Kat Kolon 4 & 16,37 \\
\hline 5 & Zemin Kat Kolon 5 & 15,80 \\
\hline 6 & Zemin Kat Kolon 6 & 17,35 \\
\hline 7 & Zemin Kt Kolon 7 & 36,14 \\
\hline 8 & 1.Kat Kolon 1 & 10,44 \\
\hline 9 & 1.Kat Kolon 2 & 11,48 \\
\hline 10 & 1.Kat Kolon 3 & 13,65 \\
\hline 11 & 1.Kat Kolon 4 & 15,06 \\
\hline 12 & 1.Kat Kolon 5 & 13,22 \\
\hline 13 & 1.Kat Kolon 6 & 11,39 \\
\hline 14 & 1.Kat Kolon 7 & 10,61 \\
\hline 15 & 2.Kat Kolon 1 & 16,49 \\
\hline 16 & 2.Kat Kolon 2 & 36,38 \\
\hline 17 & 2.Kat Kolon 3 & 13,38 \\
\hline 18 & 2.Kat Kolon 4 & 16,43 \\
\hline 19 & 2.Kat Kolon 5 & 11,55 \\
\hline 20 & 2.Kat Kolon 6 & 15,34 \\
\hline 21 & 2.Kat Kolon 7 & 10,65 \\
\hline 22 & 3.Kat Kolon 1 & 12,16 \\
\hline 23 & 3.Kat Kolon 2 & 28,42 \\
\hline
\end{tabular}




\begin{tabular}{l|l|l}
\hline 24 & 3.Kat Kolon 3 & 11,97 \\
\hline 25 & 3.Kat Kolon 4 & 12,73 \\
\hline 26 & 3.Kat Kolon 5 & 9,60 \\
\hline 27 & 3.Kat Kolon 6 & 15,97 \\
\hline 28 & 3.Kat Kolon 7 & 12,47 \\
\hline
\end{tabular}

Binanın betonarme taşıyıcı elemanlardaki donatı sayısı ve donatı çaplarının belirlenebilmesi amacıyla bu elemanların yüzeyinde sıyırma işlemleri yapılmıştır (Şekil 3).
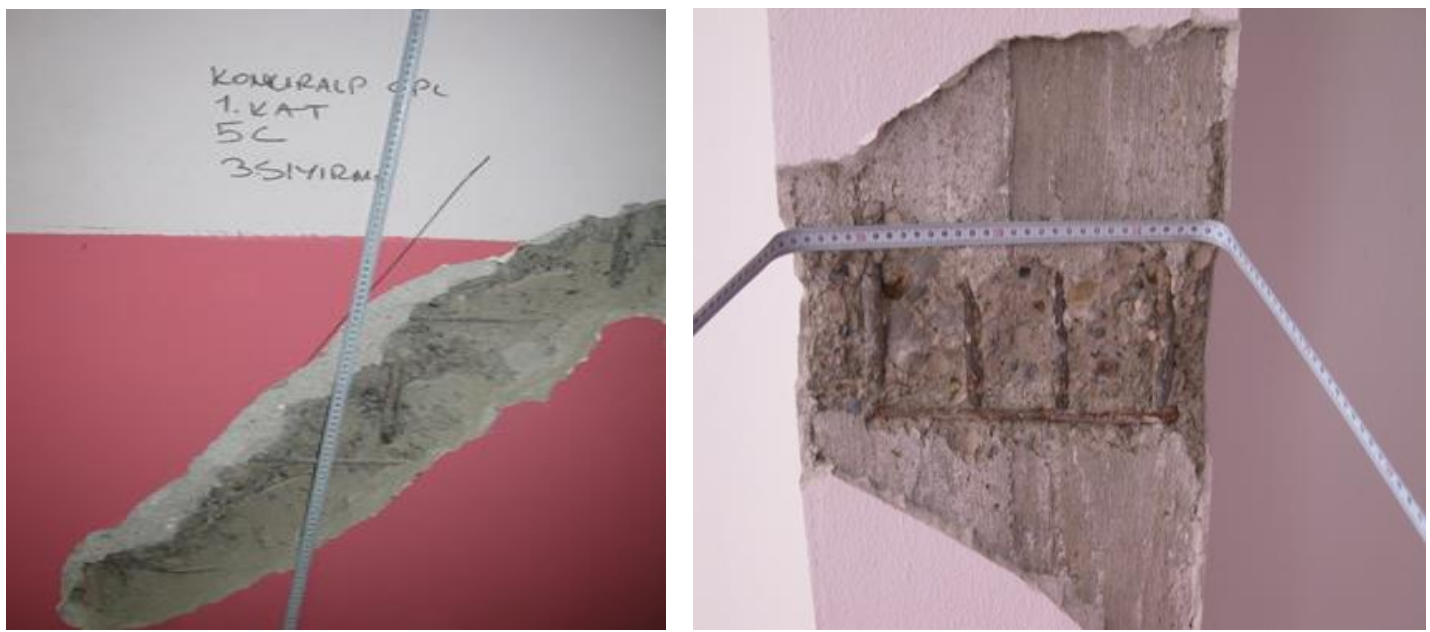

Şekil 3.Betonarme elemanlarda donatının sıyrılması

Sıyırma yapılmayan kolon, kiriş, perde gibi betonarme elemanlardaki donatıların sayısı ve çaplarının tespiti amacıyla da donatı tespit cihazları ile donatı tespitleri yapılarak incelenen yapının malzeme özellikleri belirlenmiştir (Şekil 4).

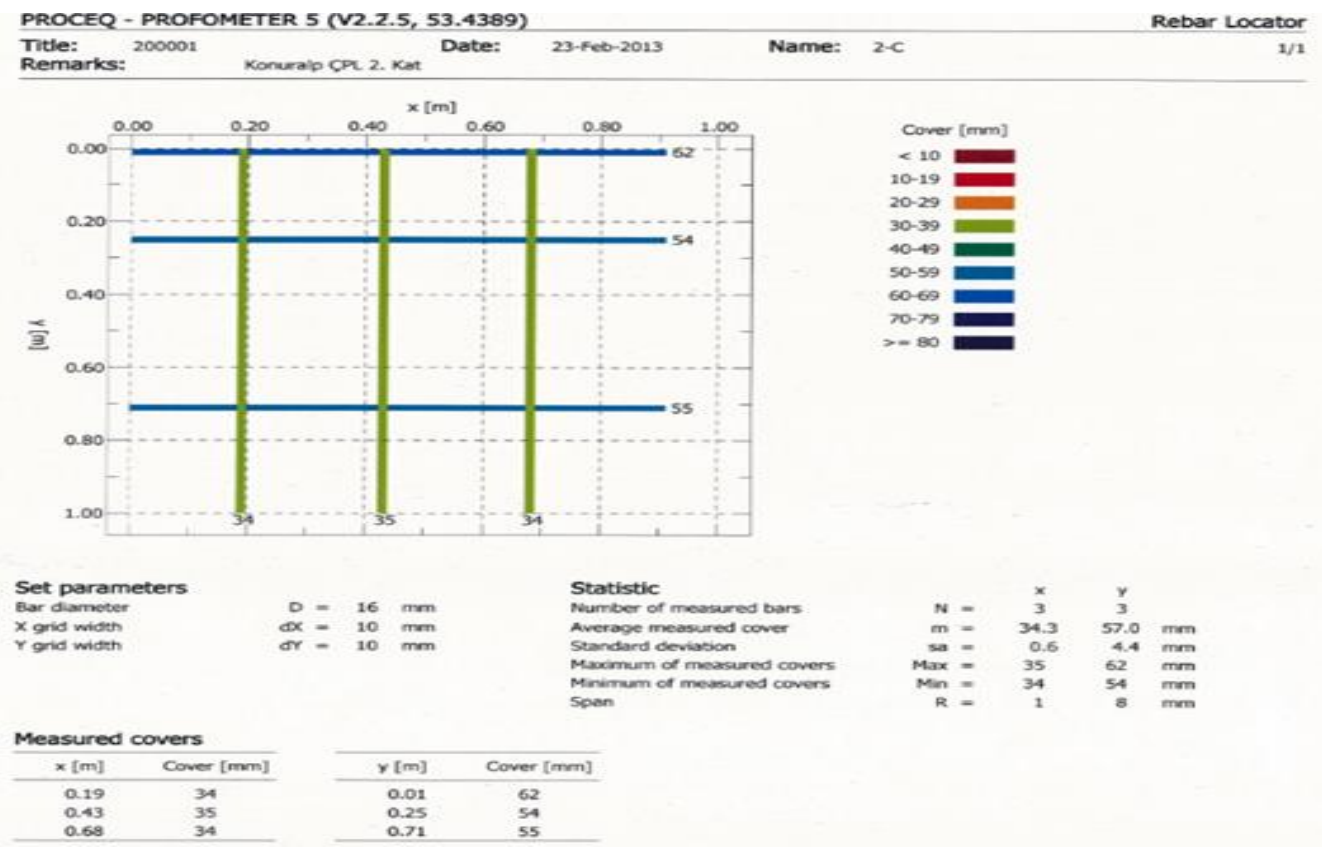

Şekil 4. Binanın 2. Katında Profometer cihazı ile donatı tespiti

Konuralp Çok Programlı Lise binasının tüm katlarında sıyırma yapılan betonarme elemanlardaki donatılar tespit edilerek Tablo 3'de verilmiştir. 
Tablo 3. Katlara Göre Slyırma Yapılan Betonarme Elemanlar ve Donatı Durumları

\begin{tabular}{|c|c|c|c|c|c|c|c|c|c|c|c|c|}
\hline & & \multicolumn{11}{|c|}{ DONATI SIYIRMA TESPIT FORMU } \\
\hline & & \multicolumn{4}{|c|}{ Okulun Adı / Binası } & \multicolumn{7}{|c|}{ KONURALP ÇOK PROGRAMLI LİSESİ BİNASI } \\
\hline & & \multicolumn{4}{|l|}{ Tarih } & & & & & & & \\
\hline \multirow{2}{*}{\multicolumn{2}{|c|}{$\begin{array}{l}\text { Yapı elemanın } \\
\text { yeri }\end{array}$}} & \multicolumn{4}{|c|}{ Yapım şekli } & \multicolumn{3}{|c|}{ Betonarme Karkas } & $\mathrm{x}$ & \multicolumn{2}{|c|}{ Betonarme Yığma } & \\
\hline & & \multicolumn{4}{|c|}{ Kat sayısı } & \multirow{2}{*}{\multicolumn{2}{|c|}{$\begin{array}{c}\text { Bodrum kat yok } \\
\text { Esas Donatı }\end{array}$}} & \multirow{2}{*}{\multicolumn{2}{|c|}{$\begin{array}{c}\text { Zemin Kat } \\
\text { Etriye/Dağıtma } \\
\text { Donatısı }\end{array}$}} & \multicolumn{2}{|l|}{ Normal kat } & $\begin{array}{c}\text { Çatı katı } \\
\text { yok }\end{array}$ \\
\hline \multirow[b]{2}{*}{$\begin{array}{l}\mathrm{S} \\
\mathrm{N}\end{array}$} & \multirow{2}{*}{$\begin{array}{l}\text { Elemanın } \\
\text { adı } \\
\text { Dosya } \\
\text { kayıt no }\end{array}$} & \multirow{2}{*}{$\begin{array}{l}\text { Eleman } \\
\text { Türü }\end{array}$} & \multirow{2}{*}{$\begin{array}{l}\text { Pas } \\
\text { pay1 } \\
\text { mm }\end{array}$} & \multicolumn{2}{|c|}{ Esas Donatı } & & & & & \multirow[b]{2}{*}{ Sıklaştırma } & \multirow[b]{2}{*}{ Filiz } & \multirow[b]{2}{*}{ Korozyon } \\
\hline & & & & $\begin{array}{l}\text { Çap } \\
\text { mm }\end{array}$ & $\begin{array}{c}\text { Adet / } \\
\text { Aralık } \\
\mathrm{cm}\end{array}$ & $\begin{array}{l}\text { Çap } \\
\text { mm }\end{array}$ & $\begin{array}{c}\text { Adet / } \\
\text { Aralık } \\
\mathrm{cm}\end{array}$ & $\begin{array}{l}\text { Çap } \\
\text { mm }\end{array}$ & $\begin{array}{c}\text { Adet / } \\
\text { Aralık } \\
\mathrm{cm}\end{array}$ & & & \\
\hline 1 & Z.Kat 4D & Kolon & 20 & 20 & 4 & & & 8 & 25 & Yok & Var & Yok \\
\hline 2 & $6 \mathrm{D}$ & Kolon & 40 & 22 & 4 & & & 8 & 25 & Yok & Var & Yok \\
\hline 3 & $7 \mathrm{E}$ & Kolon & 30 & 20 & 3 & & & 8 & 24 & Yok & Yok & Yok \\
\hline 4 & $4 \mathrm{C}$ & Kolon & 45 & 20 & 3 & & & 8 & 30 & Yok & Yok & Yok \\
\hline 5 & 1.Kat 5C & Kolon & 20 & 16 & 3 & & & 8 & 24 & Yok & Yok & Yok \\
\hline 6 & $7 \mathrm{C}$ & Kolon & 20 & 16 & 3 & & & 8 & 22 & Yok & Yok & Yok \\
\hline 7 & $8 \mathrm{D}$ & Kolon & 40 & 16 & 3 & & & 8 & 24 & Yok & Yok & Yok \\
\hline 8 & $3 C$ & Kolon & 30 & 16 & 3 & & & 8 & 22 & Var & Var & Yok \\
\hline 9 & 2.Kat $2 \mathrm{C}$ & Kolon & 30 & 16 & 3 & & & 8 & 28 & Yok & Yok & Yok \\
\hline 10 & $5 \mathrm{D}$ & Kolon & 15 & 16 & 3 & & & 8 & 26 & Yok & Yok & Yok \\
\hline 11 & $6 \mathrm{C}$ & Kolon & 25 & 16 & 2 & & & 8 & 24 & Yok & Var & Yok \\
\hline 12 & $7 \mathrm{D}$ & Kolon & 35 & 16 & 2 & & & 8 & 25 & Yok & Yok & Yok \\
\hline 13 & 3.Kat $2 \mathrm{C}$ & Kolon & 45 & 16 & 3 & & & 8 & 21 & Yok & Yok & Yok \\
\hline 14 & $5 \mathrm{D}$ & Kolon & 15 & 16 & 3 & & & 8 & 21 & Yok & Yok & Yok \\
\hline 15 & $6 \mathrm{C}$ & Kolon & 35 & 16 & 3 & & & 8 & 22 & Yok & Yok & Yok \\
\hline 16 & $7 \mathrm{D}$ & Kolon & 25 & 16 & 3 & & & 8 & 19 & Yok & Yok & Yok \\
\hline
\end{tabular}

\section{PERFormans ANALİi}

2018 Deprem yönetmeliği açısından Performans Analizi STA4-CAD V.14,1 uygun yapılan Konuralp Çok Programlı Lisesi Binasının Temel aplikasyon planı ve kalıp teçhizat planı örneği için 1. kata ait kalıp planı Şekil 5 ve Şekil 6'da verilmiştir. 


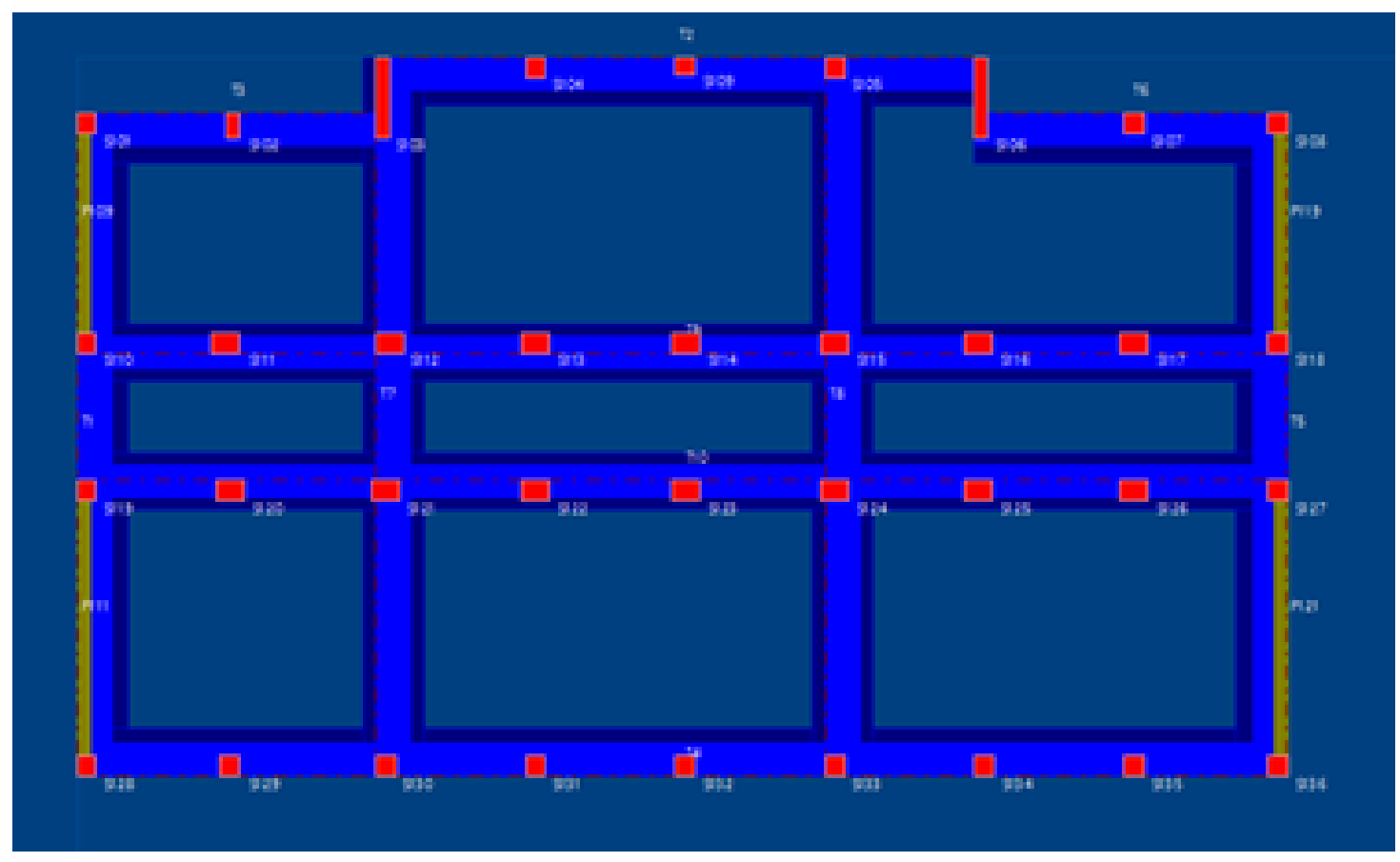

Şekil 5. Binanın Temel Aplikasyon Planı

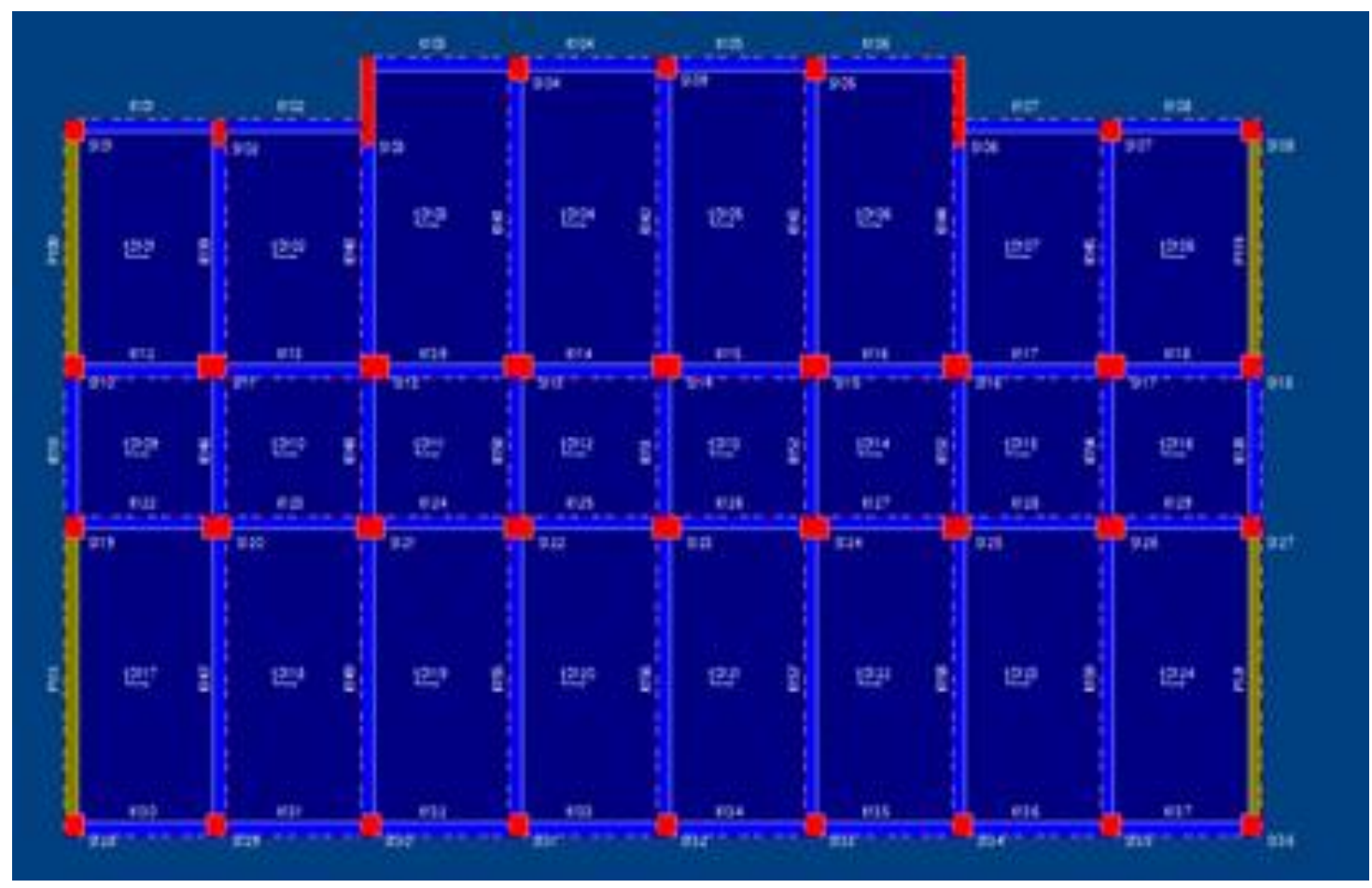

Şekil 6. 1 Kat Kalıp Aplikasyon Planı 
Binanın Performans analizleri STA4-V14.1 deprem performans analizi yapılmış ve kiriş hasar sonuçlar Tablo 4'de verilmiştir.

Tablo 4. Kiriş Hasar Yüzdeleri

\begin{tabular}{|c|c|c|c|c|c|c|c|c|c|c|c|c|c|c|c|c|}
\hline \multirow{2}{*}{$\begin{array}{l}\text { Kat } \\
\text { No }\end{array}$} & \multicolumn{4}{|c|}{$(-X)$} & \multicolumn{4}{|c|}{$(+X)$} & \multicolumn{4}{|c|}{$(-Y)$} & \multicolumn{4}{|c|}{$(+\mathrm{Y})$} \\
\hline & $\mathrm{MH}$ & $\overline{\mathrm{BH}}$ & $\mathrm{IH}$ & GB & $\mathrm{MH}$ & $\mathrm{BH}$ & $\mathrm{IH}$ & GB & $\mathrm{MH}$ & $\mathrm{BH}$ & $\mathrm{IH}$ & GB & MH & $\overline{\mathrm{BH}}$ & $\mathrm{IH}$ & GB \\
\hline 4 & 100 & 0.0 & 0.0 & 0.0 & 100 & 0.0 & 0.0 & 0.0 & 100 & 0.0 & 0.0 & 0.0 & 100 & 0.0 & 0.0 & 0.0 \\
\hline 3 & 100 & 0.0 & 0.0 & 0.0 & 100 & 0.0 & 0.0 & 0.0 & 100 & 0.0 & 0.0 & 0.0 & 100 & 0.0 & 0.0 & 0.0 \\
\hline 2 & 100 & 0.0 & 0.0 & 0.0 & 87.5 & 12.5 & 0.0 & 0.0 & 100 & 0.0 & 0.0 & 0.0 & 100 & 0.0 & 0.0 & 0.0 \\
\hline 1 & 59.4 & 40.6 & 0.0 & 0.0 & $\begin{array}{l}53.1 \\
\end{array}$ & 46.9 & 0.0 & 0.0 & 100 & 0.0 & 0.0 & 0.0 & 100 & 0.0 & 0.0 & 0.0 \\
\hline $\begin{array}{c}\mathrm{Ma} \\
\mathrm{x}\end{array}$ & 100 & & & & & 46.9 & & & & & & & & & & \\
\hline
\end{tabular}

MH: Minimum Hasar, BH: Belirgin Hasar, IH: Ileri Hasar, GB: Göçme

Binanın Performans analizleri yapılmış ve kolon kesme kuvveti dağılımı ile ilgili sonuçlar Tablo 5'de verilmiştir.

Tablo 5. Kolon Kesme Kuvveti Dă̆glımı

\begin{tabular}{|c|c|c|c|c|c|c|c|c|c|c|c|c|c|c|c|c|}
\hline $\mathrm{Ka}$ & \multicolumn{4}{|c|}{$(-X)$} & \multicolumn{4}{|c|}{$(+X)$} & \multicolumn{4}{|c|}{$(-Y)$} & \multicolumn{4}{|c|}{$(+\mathrm{Y})$} \\
\hline $\begin{array}{c}\mathrm{t} \\
\text { No }\end{array}$ & MH & $\mathrm{BH}$ & $\mathrm{IH}$ & GB & MH & $\mathrm{BH}$ & $\mathrm{IH}$ & GB & $\mathrm{MH}$ & $\mathrm{BH}$ & $\mathrm{IH}$ & GB & $\mathrm{MH}$ & $\mathrm{BH}$ & $\mathrm{IH}$ & $\begin{array}{l}G \\
B\end{array}$ \\
\hline 4 & 92.1 & 7.93 & 0.0 & 0.0 & 91.3 & 8.7 & 0.0 & 0.0 & 100 & 0.0 & 0.0 & 0.0 & 100 & 0.0 & 0.0 & 0 \\
\hline 3 & 24.3 & 71.3 & 4.4 & 0.0 & 24.2 & 71.9 & 3.9 & 0.0 & 100 & 0.0 & 0.0 & 0.0 & 100 & 0.0 & 0.0 & 0 \\
\hline 2 & 0.0 & $\begin{array}{l}95.1 \\
\end{array}$ & 3.4 & 1.5 & 0.0 & 95.3 & 4.0 & 0.7 & 100 & 0.0 & 0.0 & 0.0 & 100 & 0.0 & 0.0 & 0 \\
\hline 1 & 28.5 & 71.5 & 0.0 & 0.0 & 28.7 & 71.3 & 0.0 & 0.0 & 100 & 0.0 & 0.0 & 0.0 & 100 & 0.0 & 0.0 & 0 \\
\hline $\mathrm{M}$ & & 93.0 & 4.4 & 1.5 & & 95.3 & & & 100 & & & & 100 & & & \\
\hline
\end{tabular}

MH: Minimum Hasar, BH: Belirgin Hasar, IH: Ileri Hasar, GB: Göçme

Binanın Performans analizleri yapılmış ve alt, üst kesimlerde min. hasar bölgesini aşan kolonların kesme kuvveti dağılımı Tablo 6'da verilmiştir.

Tablo 6. Alt ve Üst Kesitlerde Minimum Hasar Bölgesini Aşan Kolonların Kesme Kuvveti Dağılımı

\begin{tabular}{|c|c|c|c|c|c|c|c|c|}
\hline \multirow{2}{*}{$\begin{array}{c}\text { Kat } \\
\text { No }\end{array}$} & \multicolumn{2}{|c|}{$(-\mathrm{X})$} & \multicolumn{2}{|c|}{$(+\mathrm{X})$} & \multicolumn{2}{|c|}{$(-\mathrm{Y})$} & \multicolumn{2}{|c|}{$(+\mathrm{Y})$} \\
\cline { 2 - 9 } & $\mathrm{MH}$ & $\mathrm{BH}+\mathrm{IH}+\mathrm{GB}$ & $\mathrm{MH}$ & $\mathrm{BH}+\mathrm{IH}+\mathrm{GB}$ & $\mathrm{MH}$ & $\mathrm{BH}+\mathrm{IH}+\mathrm{GB}$ & $\mathrm{MH}$ & $\mathrm{BH}+\mathrm{IH}+\mathrm{GB}$ \\
\hline 4 & 100 & 0.0 & 100 & 0.0 & 100 & 0.0 & 100 & 0.0 \\
\hline 3 & 100 & 0.0 & 100 & 0.0 & 100 & 0.0 & 100 & 0.0 \\
\hline 2 & 30.1 & 69.9 & 30.2 & 69.8 & 100 & 0.0 & 100 & 0.0 \\
\hline 1 & 80.3 & 19.7 & 78.1 & 21.9 & 100 & 0.0 & 100 & 0.0 \\
\hline Max & 100 & 69.9 & & & & & & \\
\hline
\end{tabular}

MH: Minimum Hasar, BH: Belirgin Hasar, IHH: Illeri Hasar, GB: Göçme 
Yapılan analizler sonucunda yapının güçlendirilmesi gerektiği tespit edilmiş olup güçlendirilmesi gereken kolon ve kirişler ile ilgili bilgiler " $x$ " ve " $y$ " yönleri için tablo halinde gösterilmiştir.

Can güvenliği sağlamayan eleman dağglımı Tablo 7'de verilmiştir.

Tablo 7. Can Güvenliğini Să̆lamayan Eleman Dă̆glımı

\begin{tabular}{|c|c|c|c|c|}
\hline \multirow{2}{*}{$\begin{array}{c}\text { KAT } \\
\text { NO }\end{array}$} & \multicolumn{2}{|c|}{ X YÖNÜ } & \multicolumn{2}{c|}{ Y YÖNÜ } \\
\cline { 2 - 5 } & Kiriş $(\%)$ & Kolon $(\%)$ & Kiriş $(\%)$ & Kolon $(\%)$ \\
\hline 4 & $0 / 32(\% 0.0)$ & $0 / 40(\% 0.0)$ & $0 / 23(\% 0.0)$ & $0 / 40(\% 0.0)$ \\
\hline 3 & $0 / 32(\% 0.0)$ & $4 / 40(\% 10.0)$ & $0 / 23(\% 0.0)$ & $0 / 40(\% 0.0)$ \\
\hline 2 & $0 / 32(\% 0.0)$ & $5 / 40(\% 12.5)$ & $0 / 23(\% 0.0)$ & $0 / 40(\% 0.0)$ \\
\hline 1 & $0 / 32(\% 0.0)$ & $0 / 40(\% 0.0)$ & $0 / 23(\% 0.0)$ & $0 / 40(\% 0.0)$ \\
\hline
\end{tabular}

\section{SONUC VE TARTIȘMA}

Binanın mimari özellikleri, binada kullanılan beton ve donatı özellikleri, binanın temeli, statik özellikleri vb. açılardan çok yönlü olarak değerlendirilmiştir. 2018 Deprem Yönetmeliğine göre "yapılacak tüm betonarme binalarda C25'ten daha düşük dayanımlı beton kullanılamaz" ifadesi geçmektedir[4]. Bu açıdan değerlendirildiğinde söz konusu binanın beton basınç dayanımının yönetmelikte tanımlanan basınç dayanımı değerinin altında olduğu anlaşılmaktadır. Zemin Etüt Raporunda, incelenen binanın zemininde 4,5 m derinlikte 2 adet kuyuda sondaj çalışmaları yapılmış ve bu kuyularda yer altı suyuna rastlanmamıştır.

Sondaj kuyularından alınan numunelerin mekanik özelliklerinin belirlenmesi amacıyla Nokta Yükleme deneyi yapılmış ve en düşük taşıma gücü değeri $12.81 \mathrm{~kg} / \mathrm{cm}^{2}$ ile SK-1 kuyusundan 3,0-4,5 m derinlikten alınan numuneden elde edilmiştir. Güvenlik katsayısı 10 olarak alındığında Zeminin Emniyetli Taşıma Gücü değeri qem=1.28 kg/ $\mathrm{cm}^{2}$ olarak hesaplanmıştır. İncelenen zeminde 1 adet sismik çalışma yapılmış olup 1.tabaka kalınlığının yaklaşık $1.0 \mathrm{~m}$ civarında olduğu 2.tabaka kalınlığının ise 8,0 m'den fazla olduğu tespit edilmiştir. Sismik analizlerin sonucunda 1.tabakada zemin emniyet gerilmesi $0.96 \mathrm{~kg} / \mathrm{cm}^{2}$ ve 2 .tabakada zemin emniyet gerilmesi ise $4.48 \mathrm{~kg} / \mathrm{cm}^{2}$ olarak belirlenmiştir.

Zemin Etüt Raporundaki Sismik çalışmaların sonuçları ve Mekanik Deney sonuçları (Nokta Yükleme Basınç Deneyi) bir bütün olarak değerlendirildiğinde Zeminin Emniyetli Taşıma gücü değerinin S1 sismik çalışmasında 1.tabaka için qem $=0.96 \mathrm{~kg} / \mathrm{cm}^{2}$ olduğu belirtilmiştir. Diğer taraftan Nokta yükleme deney sonuçlarına göre de zeminin taşıma gücü değerinin qem=1.28 $\mathrm{kg} / \mathrm{cm}^{2}$ olarak hesaplandığ görülmüştür. Her iki durum birlikte değerlendirildiğinde sismik çalışma sonuçlarının da dikkate alınması gerektiği ve bu nedenle güvenli bölgede kalmak amacıyla Zeminin Emniyetli Taşıma gücünün qem=1.10 kg/ $\mathrm{cm}^{2}$ olarak alınmasının uygun olacağı düşünülmektedir. Zemin yatak katsayısı ise 3000-5000 ton $/ \mathrm{m}^{3}$ arasında belirlenmiş olup güvenli kısımda kalmak amacıyla zeminin yatak katsayısının 3000 ton $/ \mathrm{m}^{3}$ olarak alınmasının uygun olacağı düşünülmektedir. İncelenen zeminin, Deprem Bölgelerinde Yapılacak Yapılar Hakkında Yönetmeliğe göre B Zemin Grubunda ve Z1 Yerel Zemin Sınıfında olduğu belirlenmiştir. İncelenen okul binası beton basınç dayanımları, taşıyıcı elemanlarındaki donatı miktarları, temel özellikleri ve zemin özelliklerine bağlı olarak 2018 deprem yönetmeliğine göre performans analizi yapılmıştır. Analiz sonucunda binada güçlendirme yapılması 
gerektiği anlaşılmış ve güçlendirilecek elemanlarla ilgili bilgilerde tablo halinde özet olarak verilmiştir. $\mathrm{Bu}$ durumda, ivedi olarak binanın güçlendirme projesinin hazırlanması gerektiği ve yönetmelikte belirtilen şartlar dâhilinde güçlendirilerek kullanılabileceği değerlendirilmektedir.

\section{KAYNAKLAR}

[1] JICA Türkiye'de Doğal Afetler Konulu Ülke Strateji Raporu, JICA. Ankara,29, 2004

[2] Küçük, D., "Deprem Zararlarını Azaltma Çalışmalarında Mimarlık Eğitiminin Yeri,” Yüksek Lisans Tezi, Gazi Üniversitesi Fen Bilimleri Enstitüsü, Ankara, 2006.

[3] ATC, "Seismic Evalution and Retrofit of Concrete Buildings (ATC-40)", Applied Technology Council, Redwood City, California, 1996.

[4] TBDY 2018 Deprem Etkisi Altında Binaların Tasarımı için Esaslar, Ankara, 2018.

[5] Bayülke, N., "Depremde Hasar Gören Yapıların Onarım ve Güçlendirilmesi" İnşaat Mühendisleri Odası İzmir Şubesi Yayın No:15 sayfa:13, İzmir,1999.

[6] Ersoy, Uğur., "Betonarme, Temel İlkeler ve Taşıma GÜCÜ Hesabı,” Evrim Yayınevi, İstanbul, 2006.

[7] Celep, Z., Kumbasar, N., "Deprem Mühendisliğine Giriş ve Depreme Dayanıklı Yapı Tasarımı" Beta Dağıtım, İstanbul, 2004.

[8] STA4-V14.1 "Structural Analysis for Computer Aided Design" user guide.

[9] SAP2000, Integrated Finite Element Analysis and design of Structures, 2010.

[10] FEMA, P., Commentray for the seismic rehabilitation of buildings, FEMA-356, Federal Emergency Management Agency, Washington, DC, DOI 2000.

[11] Calvi, G. M., Pinho, R., Manages, G., Bommer, J.J., Restrepo-Velez. L, F., Crowley. H., Development of Seimic Vulnerability Assessment Methodologies Over the Past 30 Years, ISET Journal of Earthquake Technology, 43,75-104, 2006.

[12] TSE 500 "Betonarme Yapıların Tasarım ve Yapım Kuralları, Türk Standartları Enstitüsü, 2000.

[13] Celep. Z., "Betonarme Sistemlerde Doğrusal Olmayan Davranış: Plastik Mafsal Kabulü ve Çözümleme”, 6. Ulusal Deprem Mühendisliği Konferansı, İstanbul, 16-20 Ekim 2007.

[14] Kap,T., Özgan, E., Uzunoğlu, M.M., "Taşıma Gücü Zayıf Zeminde İnşa Edilmiş Betonarme Bir Binanın Performans Analizi” Düzce Üniversitesi Bilim ve Teknoloji Dergisi, Cilt:1, S:795-809, 2019. 
[15] Tunç, G., ve Tanfener, T., "2007 ve 2016 Türkiye Bina Deprem Yönetmeliklerinin Örneklerle Mukayesesi”, 3.Ulusal Yapı Kongresi ve Sergisi Teknik Tasarım, Güvenlik ve Erişebilirlik, TMMOB Mimarlar Odası Ankara Şubesi, 2016. 